\title{
15 \\ Teaching citizenship in visual communication design: reflections of an Afrikaner
}

\author{
Elmarie Costandius
}

\section{Introduction}

\begin{abstract}
$\mathrm{n}$ academic institution's focus of learning is usually on students, while the learning of lecturers is often regarded as being of secondary importance. Is it true, as the old adage has it, that the best way to learn is to teach? And, if so, is the learning that takes place mostly content-driven learning or reflective? This chapter describes the learning that occurred through a citizenship module that aimed to change the perceptions and attitudes of students, and also my own reflective experience of the process, which I realised was also a journey in personal learning.

The introduction of a module on citizenship in the visual communication design syllabus led me to valuable reflection on my emotional limitations to facilitate a module of this nature. During my guidance of the module I experienced vulnerability, fear and guilt. Even though it was not an easy journey, this module was the most rewarding teaching endeavour I have experienced; it connected my teaching with my everyday life.

In this chapter I present a summary of the module on citizenship. Then I describe the different perspectives on self-reflection described in the literature, and the memories and emotions that were triggered in me during the module. I also reflect on what I learned in the process.
\end{abstract}




\section{Describing the citizenship module}

The citizenship module was incorporated into the visual communication design curriculum at the Visual Arts Department at Stellenbosch University and brought together first- to third-year students and Grade 11 high school learners from Kayamandi (previously and still predominantly a black suburb of Stellenbosch). Working in the context of Stellenbosch University is complex because of its historical association with apartheid and its mostly white Afrikaans student population.

The module began with the school students and university students reading articles or chapters in books, followed by group discussions in the community interaction sessions in which both groups participated. The aim was to facilitate direct and deep learning by considering such themes as blackness/whiteness, stereotyping, power relations, discrimination, helping behaviour, risk and social memory.

Information gained from the conversations was then visually expressed in a typographical layout. Representing issues visually, finding metaphors, discovering new and unexpected combinations or creating multiple interpretations are all ways of dealing with sensitive issues mentally as well as on a physical level. In his book The Arts Therapies: a revolution in healthcare, Jones (2005) emphasises the importance of art in therapy by stressing the relationship between art and the unconscious and the potential for change.

Reflective writing was used as a method to contemplate actions and reactions in the community exchanges. After each community interaction, and at the end of the module, students wrote structured reflections (Eyler, 2002) on their experiences. To encourage personal emotions to surface, while simultaneously placing them in a theoretical context, the AffectiveCognitive model (Smith-Tolken and du Plessis, 2009) was used.

The methodology for the module, Action Learning and Action Research (ALAR), enabled community members, students and the lecturer to take part together (Zuber-Skerritt, 2003). The theoretical framework that guides the ALAR process is constructed of grounded theory: raw data and contextual knowledge; personal construct theory: active constructors of knowledge; critical theory: self-critical attitudes; and systems theory: holistic resolutions to complex problems (Zuber-Skerritt, 2003). The aim was not to arrive at generalisations but to get to know, understand and enhance social transformation for the benefit of all the participants. 


\section{Perspectives on self-reflection}

In the literature terms like 'metacognition', 'self-study' or 'self-reflectiveness' are used to describe the process in which the self is taken as the object of investigation to acquire an identity as a critical thinker by developing an ability to look inside oneself. Reflective thinking is apparent in oral and early written literature but Kant, Marx and Freud were amongst the first writers to verbalise and formulate this approach. In the field of education, opinions differ as to what is seen as self-reflection and what its major advantages are. Dewey (1910:13) argues that 'reflective thinking is always more or less troublesome because it involves overcoming the inertia that inclines one to accept suggestions at their face value; it involves willingness to endure a condition of mental unrest and disturbances.' For Jaspers (1963), self-reflection includes self-observation, self-revelation and self-understanding. Habermas (1978) defines reflection as practising critical self-determination. Mezirow (1998:185) suggests that meaningful personal and social transformation may result from self-reflection, to the benefit of ethical and moral development. Schön (1987) maintains that reflection is a consistent process of self-involvement in what he calls 'reflection in action'.

The value and function of self-reflection is described extensively in academic literature but the actual process that takes place in one's mind when reflecting has yet to be fully unexplored. The relationship between a person's conscious and unconscious mind is therefore not wholly understood (Schön, 1987). The subconscious and conscious minds might be operating in a closer relationship than has so far been realised. As Yip (2007:294) argues: 'The gap between the intended mindfulness and unintended unconscious is lessened by a spontaneous self-reflection.'

Writing a self-reflection as an Afrikaner makes whiteness central to the reflection. Steyn (2005:133) reflects on whiteness in South Africa as a complex hybrid identity and urges a 'continuing need to build self-reflexivity amongst white people'. Vice (2010) wrote a self-reflection on whiteness, urging whites in South Africa to be humble and not perpetuate whiteness. In this chapter, my reflections revolve mostly around contemplations of whiteness and aspects related to it.

Self-reflection is a 'self-constructed process that is influenced by social, cultural, political and organizational contexts' (Yip, 2007:296). Historically and currently I am classified as white and, more specifically, a white Afrikaner. I write this reflection from this constructed perspective because I cannot get away from it, and though I would have liked to write as a neutral human 
being, I am caught in my socially constructed identity. I would not like to write on behalf of all white Afrikaners, however, because there are many differences within this group. When I read Jansen's Knowledge in the Blood (2009), I frequently identified myself with the opinions that he formulates but I also sometimes felt that he describes an Afrikaner I do not associate with. What this chapter contains is therefore a constructed self-reflection from a constructed self-identity. Writing this self-reflection down could give the impression that it is fixed and final but it is in fact a process of continuous reconstruction.

\section{Reflections on my learning process}

Here I describe the issues and emotions triggered during the citizenship module, and reflect on the personal learning I experienced because of these emotions.

The module brought back memories of my childhood and upbringing. I grew up without openly discussing politics and the church, the two issues my mother said were like millstones around our necks, preventing us from breaking out of our Afrikaner conservatism. Up to the late 19th century Afrikaans people displayed few nationalistic tendencies because of their strong individualistic inclinations (Nel, 1979). On 8 November 1876 De Zuid-Afrikaan wrote, 'Hy moet national selfrespect leeren' ([The Afrikaners] need to learn national self-respect), and the decision was taken to make teachers the carriers of nationalist messages (Nel, 1979:4). By the early 1990s Afrikaner politics, religion and education were intertwined. The development of Afrikaner nationalism was hugely successful and one becomes fearful when looking back at how easily people can be influenced - especially when an educational system is used as the medium. The module reminded me of the huge responsibility and power a lecturer has, and how conscious and careful they need to be not to misuse this power.

When I was guiding the module there were times I asked myself why I was doing it, as it required a huge amount of time and emotional energy. I must admit that I am still not sure as to what single impetus drove my actions, but speaking generally I can say that I act in any particular way because I believe it is the right thing to do. At the same time, however, a complex set of emotions often accompanies my belief that a certain thing is the right thing to do. I wonder how great an influence white guilt about the past, both individual and collective, has had on my actions. This reminds me of Biko's words about the 'vague satisfaction for the guilt-stricken whites' (2004:23). Would a module like this give me a password that would permit me to live with myself 
and sleep without the heavy burden of whiteness? Would I be able, now, to say that I broke the silence and faced the issues openly, or are religious motivations subconsciously driving my actions? Though I would like to believe that I present the citizenship module purely because I believe it to be ethically correct, I cannot ignore the fact that my motivation is undoubtedly more complex and layered.

Each person who reflects on the possibilities of dealing with the Afrikaner past - from denial to open confession - is probably filled with self-doubt, resentment and fear, although these feelings might manifest themselves in different forms. I personally believe that ignoring the little voice of conscience that reminds one of the past might be a dangerous thing to do, since these feelings might then surface in other ways. A suppressed feeling cannot be psychologically healthy. Through the citizenship module, I became more interested in what my subconscious can hide from my conscious mind and faced the challenge of trying to unpack and understand my feelings and actions.

I believe the wrongs of the past should be corrected. By saying this I acknowledge that all people should have a fair chance to succeed. The module again made me realise that it is necessary for both white students and me to understand what it means to be a person of colour, and to critically reflect on whiteness, the invisible privileges of being white, the consequences of institutional whiteness and what is considered the norm. Owing to the interactions involved in the module, I learned that talking about and realising what white privilege involves represents only a first step; actually giving up my privileges would be a far more challenging next step.

My education at Pretoria University years ago was filled with messages that 'white is good' and 'the other is substandard'. African art, for instance, did not feature in our curriculum. Instead we were exposed to European art and design, as if we were living somewhere in Europe, ignoring the fact that our lives were in Africa. At the time I did not realise that there was anything wrong with that assumption; it was what I had been fed since my schooldays. Even though I question these contradictions now, I wonder how much of my education still unconsciously influences my judgement of what is good design and what is not. This is something I continually question and confront in myself.

In the citizenship module I tried to open up the space for more voices and visual expressions to emerge. A Muslim student told me after she had graduated that by encouraging her to use her religious background as inspira- 
tion for her designs, I 'othered' her even more. This incident led me to realise the narrowness of my perspective and my own limitations in 'seeing myself in the shoes of others' (Nussbaum, 2002). Encouraging students to develop their own voices is not enough; there should also be space for those students to feel comfortable enough to express a personal voice. I learned that creating an inclusive space is very much in the hands - or rather the psyche - of the lecturer.

Facing whiteness also means overcoming my fear of criticism and putting my own imperfections on show. Every time I talk about the citizenship module it feels as if I expose myself - and if I am criticised about what and how I do something, the reasons why I do it and the ways in which I do it, I feel sensitive about it. After one of my presentations, a member of the audience asked what I meant when I spoke of a safe space. A safe space to me is one where what is said during conversations in class or community interactions will not be held against the students and will not affect their marks. The man asked whether that safe space means I am not confronting issues openly and fully. He also asked why it is that people at Stellenbosch University always seem too scared to talk openly and why there is an insistence on it all happening in a safe space. Theoretically I distinguished between safe space and 'safe speech' (Waghid, 2004) and I thought I had it resolved in my own mind. However, if I go deep inside myself, I realise that I do need a safe space so I can come to terms with my whiteness, and there are aspects of safe speech included in this concept.

I put myself in that uncomfortable space by taking on the citizenship module and talking about it at seminars and conferences, but it has also brought new insights and forced me to admit to contradictions in my own mind. The day after the seminar I seriously considered whether I should discontinue the module and simply return to teaching my design curriculum. Afterwards, I realised that it was positive criticism that helped me understand things in greater depth. The journey continues, because by writing this reflection and publishing it, I am again opening myself to criticism.

The issue of doing good, connected with religious belief systems, surfaced in conversations during the citizenship module. This again made me think of what my potential motivation for taking on this module might be and whether it was somehow influenced by my Christian upbringing. I remember my mother once saying that she did not fulfil her dream to do missionary work; instead she was a teacher all her life. I was very conscious of her urge to help people. I often think that my urge to contribute to society might have 
had its roots in my mother's unfulfilled dream. Perhaps it is true that parents subconsciously project their own issues and desires onto their children.

Another spiritual aspect related to my mother's unfulfilled dream may have played a role in my decision to take on the citizenship module. I remember a day in my second year of undergraduate study when I prayed to God and asked him to let me pass my degree, and in return I would do missionary work. I did not study art as a school subject and originally studied law. Starting art studies late made my first two years difficult. By my fourth year I had forgotten about my promise because I felt comfortable on the course. It was years later, when I was walking in Kayamandi, that I suddenly remembered my promise. In a strange way, I felt relieved that after so many years I had done something about it at last. When I reflect on my reaction to this promise now, I realise that although religion is not playing a role in my life at present, traces of it have been left deep in my subconscious.

As a middle-class white person it is easier for me to make an emotionless contribution to poor persons of colour who are 'far' away. If I cook soup for the night shelter, I never meet the people who eat the soup. There are no emotional ties or expectations that can expose my emotions and vulnerabilities. If I teach art to a learner, I do not have to question why I do it and what it is that I really achieve with my teaching. I might believe that I do good because it will help the learner in some way, but in a broader social context it might not be good for healthy future relations because it perpetuates existing hierarchies and power relations.

It is for this reason, through the citizenship module, that I learned to be very cautious and to reflect critically on concepts such as missionary work, charity or types of helping behaviour that encourage the idea of 'white as knowledgeable and black as needy' (Biko, 2004:23) and attitudes of 'giving and receiving'. Santas (2000:349-50) remarks that teaching antiracism, therefore, is doubly prone to failure because the internalised superiority of the 'all-knowing teacher' is most often coupled with that of the 'well-meaning white person'. The charity paradigm, according to Britzman (in Kumashiro, 2000:43), affirms white superiority, since it can veil 'complicity with racism, homophobia, and other forms of oppression'.

A problematic aspect in the citizenship module was the skewed power symmetries and hierarchies between students and learners. The ideal would be for students to have conversations with peers at other universities instead of with school learners. This is something that needs to be addressed in the future. The citizenship module developed over a period of six years in close 
partnership with non-governmental organisation (NGO) Vision-K in Kayamandi. It is difficult to break that relationship but an alternative programme needs to be established for learners that will not leave the NGO feeling rejected. That 'the symmetry is not ideal' is not a good enough reason in this situation; the emotional risks involved in these types of relationships cannot easily be ignored.

Because I realised that my urge to grow was a strong driving force behind the module, I often wondered whether it meant as much to the students as it did to me. Were the students eager to participate or did they do so because it is part of their curriculum? I would like to believe that I inspired students with my own eagerness to discover new knowledge about myself in my relationships with others.

Through these experiences I learned doing so takes a huge amount of patience, and that there is a long journey ahead of me. I understand that others might not have the patience and want to see society change at a faster pace - and that is perfectly legitimate after all that happened in the colonial and apartheid past. I realise, however, that consciously changing deep-rooted perceptions and attitudes, most of which lie in the subconscious, cannot be done in a few days or weeks; it will take months or, more realistically, years. Jansen (2009) refers to the knowledge that is in the blood. He is correct: it is in my blood. My journey will be to get rid of the bad blood. Changing perceptions is a process of 'degraining' the ingrained ideas and attitudes in my mind; they need to be decolonised, de-racialised and reprogrammed.

Da Silva (2008:91) refers to whites 'privatising their feelings'. I can identify with that. There was a long silence in my life before I confronted issues openly. It was not a question of not acknowledging the wrongs of the past, but rather of determining what I needed to do about it. What kind of journey did I need to embark on to address these issues and come to terms with them psychologically? The citizenship module became the medium: a space in which I could rethink, reflect and try to re-programme my mind. I suggest to lecturers who would like to come to terms with the contentious past to incorporate it into their curricula, and in that way work collectively with students to attempt to heal the rifts that still exist in society.

Of course one cannot ignore the question of to what extent I am capable of teaching citizenship - not when I am a product of an unequal and divided past and a carrier of 'troubled knowledge' (Jansen, 2009:258). One can also ask who we can consider to be without troubled knowledge, since the influence of scars we carry from our past is undeniably transferred to our students. 
These points comprise an extract of my reflections and the emotions I experienced while involved in the citizenship module. I want to close with a last comment from a colleague, who quoted the words of Freire: 'change cannot be driven by a white person, the oppressor; it has to come from the oppressed themselves.' I agree with this; it refers to Steyn's warning about a situation where whites see themselves as the ones who should 'take charge of social transformation, in the interest of Africans' (2005:127). But does that mean I should sit back and not participate in the transformation process, as Vice (2010) argues from a white Afrikaner perspective? I should like to disagree. Each small action has the potential to contribute, although one has to be ever conscious not to perpetuate the negative perceptions and power relations of the past in the process of trying to do good. This reflection assisted me when I thought again about the citizenship module, and learnt in the process of doing so.

When one reads a chapter about citizenship in the safety of one's own home, one can only imagine the experiences and complications of such an endeavour. One can easily think, 'Yes, I agree with everything in the chapter' without changing deeply ingrained perceptions and attitudes in oneself. When one actually participates in a module focused on citizenship, however, the experience become embodied and emotional. My involvement was rich and expansive and delivered opportunities for self-reflection, so enhancing the opportunity for learning. Fourie (1999:277) calls for 'cognitive transcendence', but I believe a physical experience is more likely to trigger changes in perceptions and attitudes. My own learning regarding social transformation was invaluable - and it occurred as a result of my actual participation in the citizenship module.

\section{Concluding remarks}

Writing an article is often a huge effort; reflecting on one's own emotional state of mind makes it all-consuming. I can honestly say that it has not been an easy or comfortable journey. Zembylas writes about the pedagogies of discomfort that 'provide spaces for mourning, and transform such feelings into energy for praxis, responsibility and transformation' (2008:235). Steyn's data indicates that 'whites who are shifting their paradigm from preserving privilege for some to taking responsibility for promoting development of all have grappled with, or at least have not evaded, these uncomfortable feelings' (2005:132). But what I can say is that the citizenship module was the most rewarding teaching endeavour I have experienced. It is rewarding to reflect on and deal with issues that have been silenced for too long. 
Reflection for me came with physically experiencing and interacting, not merely reading and thinking about citizenship in the comfort of my own home. It was both a physical and a mental experience. Using art as a way of expressing emotions or dealing with sensitive issues was valuable. Even though it is not possible for all lecturers to be physically involved in community interaction, or in dealing with sensitive issues through art processes, other types of exposure could be facilitated in the form of research groups. These could function as support groups operating in a safe space to unpack the white silence and white fear that can form barriers to transformation. I have established a research group at Stellenbosch University called Critical Citizenship and any lecturer is welcome to take part in the group's conversations and activities, including seminars, workshops and research projects.

I decided to write this reflection because I hoped that personal growth would accompany such an attempt and encourage other lecturers to undertake such a journey. Kendall refers to John Kotter's book Leading Change: why transformation efforts fail, that it emphasises the first step of 'establishing a sense of urgency' (2006:20). Addressing issues of critical citizenship in curricula across all departments should be treated as a matter of urgency. Teaching critical citizenship from an Afrikaner perspective requires deep selfreflection, which is difficult and uncomfortable but is urgently needed collectively. Afrikaner nationalism was spread very successfully through education - with many negative results. But the medium of education could be used once more to reflect critically on that troubled history and contribute positively by facilitating processes of acknowledging, growing and healing.

\section{Acknowledgement}

Thank you to the Critical Professionalism research group for their valuable support and contribution that was instrumental in my own learning process.

\section{References}

Biko, S (2004) I Write What I Like. Johannesburg: Picador Africa

da Silva, T S (2008) Narrating redemption: life writing and whiteness in the new South Africa: Gillian Slovo's every secret thing. ARIEL: a review of international English literature 91-107

http://ariel.synergiesprairies.ca/ariel/index.php/ariel/article/view/2181 (accessed June 20011).

Dewey, J (1910) How We Think. Boston: DC Heath

Eyler, J (2002) Reflection: linking service and learning - linking students and communities. Journal of Social Issues 58 517-34

Fourie, M (1999) Institutional transformation at South African universities: implications for academic staff. Higher Education 38(3) 275-90

Habermas, J (1978) Knowledge and Human Interests. London: Heinemann

Jansen, J D (2009) Knowledge in the Blood: confronting race and the apartheid past. Cape Town: UCT Press 
Jaspers, K (1963) General Psychopathology. Manchester: Manchester University Press Jones, P (2005) The Arts Therapies: a revolution in healthcare. East Sussex: Brunner-Routledge Kendall, F E (2006) Understanding White Privilege; creating pathways to authentic relationships across race. New York: Routledge

Kumashiro, K K (2000) Towards a theory of anti-oppressive education. Review of Educational Research 70(1) 25-53

Mezirow, J (1998) On critical reflection. Adult Education Quarterly 48(3) 185-98

Nel, P G (1979) Die Betekenis van die Genootskap van Regte Afrikaners, die Afrikaanse Patriot en Ons Klijntji. In P G Nel (ed) Die Kultuurontplooing van die Afrikaner. Pretoria: HAUM

Nussbaum, M (2002) Education for citizenship in an era of global connection. Studies in Philosophy and Education 21 289-303

Santas, A (2000) Teaching anti-racism. Studies in Philosophy and Education 19 349-61

Schön, D A (1987) Educating the Reflective Practitioner. San Francisco: Jossey-Bass

Smith-Tolken, A and Du Plessis, J (2009) Effective learning through reflection in service learning. Paper presented at the third International Conference on Service Learning, University of Indianapolis, Indianapolis, Indiana, USA

Steyn, M (2005) 'White talk' white South Africans and the management of diasporic whiteness. In A J Lopez (ed) Postcolonial Whiteness: a critical reader on race and empire. Albany: State University of New York Press

Vice, S (2010) How do I live in this strange place? Journal of Social Philosophy 41(3) 323-42

Waghid, Y (2004) Compassion, citizenship and education in South Africa: an opportunity for transformation? Revue 50(5-6) 525-42

Yip, K-shing (2007) Self-reflection in reflective practice: a Jaspers orientation. Reflective Practice 8(2) 285-98

Zembylas, M (2008) Bearing witness to the ethics of suffering: J M Coetzee's disgrace, inconsolable mourning, and the task of educators. Studies in Philosophy and Education 28(3) 223-37 Zuber-Skerritt, O (2003) Action learning and action research in higher education. In S Speedy (ed) Women using Action Learning and Action Research: the South African context. Lismore, Australia: Southern Cross University Press 